\section{Bat-associated Rabies Virus in Skunks}

\author{
Mira J. Leslie, ${ }^{*}$ Sharon Messenger, $\uparrow$ \\ Rodney E. Rohde,‡ Jean Smith,§ \\ Ronald Cheshier, $\mathbb{T}$ Cathleen Hanlon, $\S$ \\ and Charles E. Rupprecht§
}

Rabies was undetected in terrestrial wildlife of northern Arizona until 2001, when rabies was diagnosed in 19 rabid skunks in Flagstaff. Laboratory analyses showed causative rabies viruses associated with bats, which indicated cross-species transmission of unprecedented magnitude. Public health infrastructure must be maintained to address emerging zoonotic diseases.

$I^{2}$ n North America, $>90 \%$ of cases of rabies in animals occur in wildlife (1); several mammalian taxa harbor characteristic rabies virus variants (RABVV). In Arizona, skunks (Mephitis mephitis) and gray foxes (Urocyon cinereoargenteus) maintain independent rabies enzootic cycles, and in indigenous bats, rabies has been diagnosed in 14 of 28 species (Arizona Department of Health Services, unpub. data). Although skunks live throughout Arizona, until 2001, rabid skunks had been found only in the southeastern quadrant of the state.

In the United States, bat RABVV are a source of infection for humans and other mammals (2-8). Typically, interspecies infection produces a single fatal spillover event; secondary transmission has rarely been observed. Antigenic typing of rabid carnivores in Arizona from 1996 through 2000 identified bat RABVV in 1 domestic dog and 2 gray foxes. This report describes the largest documented rabies epizootic among terrestrial mammals infected with bat RABVV, with perpetuated animal-to-animal transmission. Coincident with the zoonotic disease significance, this report provides contemporary insight into pathogen evolution (9).

\section{The Study}

In January 2001, a homeowner contacted Flagstaff Animal Control about a dead skunk. Although no human had been exposed to the skunk, tissues were submitted to the Arizona State Health Laboratory, where rabies was

*Washington State Department of Health, Shoreline, Washington, USA; †California Department of Health Services, Richmond, California, USA; łTexas State University-San Marcos, San Marcos, Texas, USA; §Centers for Disease Control and Prevention, Atlanta, Georgia, USA; and ÆArizona Department of Health Services, Phoenix, Arizona, USA diagnosed. This skunk was the first rabid terrestrial wild carnivore reported from the area. The Texas Department of State Health Services subsequently identified an RABVV associated with bats in tissues sent for antigenic characterization. From January through April, 14 more skunks, dead or exhibiting abnormal behavior, were found throughout a large residential subdivision within $4 \mathrm{~km}$ of the initial case. All were infected with the same bat RABVV. From April through July, 4 more skunks infected with bat RABVV were identified $\approx 9 \mathrm{~km}$ west of the initial focus (Figure 1). Control measures included prohibiting relocation of nuisance skunks, comprehensive public education, pet rabies vaccine clinics, and a 90-day emergency quarantine requiring pets to be leashed or confined and vaccinated (Figure 1). Additionally, 217 urban skunks were vaccinated and marked with ear tags during a 6-month phased program of trap, vaccinate, and release.

In Flagstaff and the surrounding county, during the decade before this epizootic, 2 rabid bats, on average, were reported each year. During the epizootic, 218 animals were submitted for rabies testing (Table). Rabies was confirmed in 19 (13\%) of 145 tested skunks and 2 (9\%) of

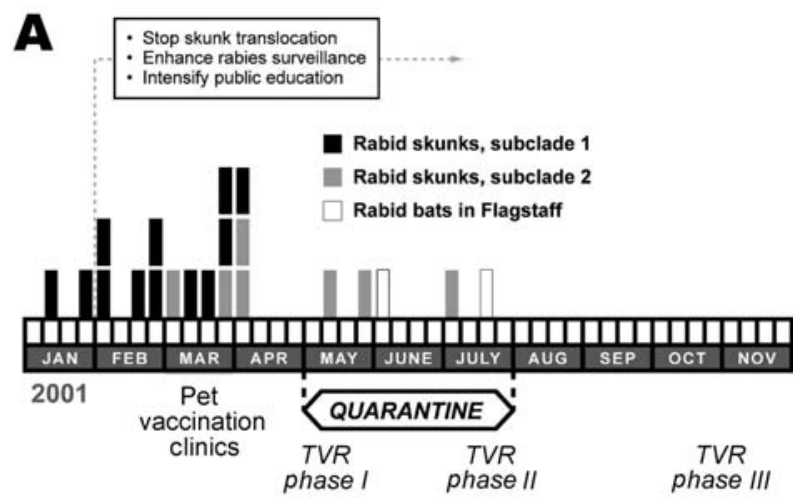

B

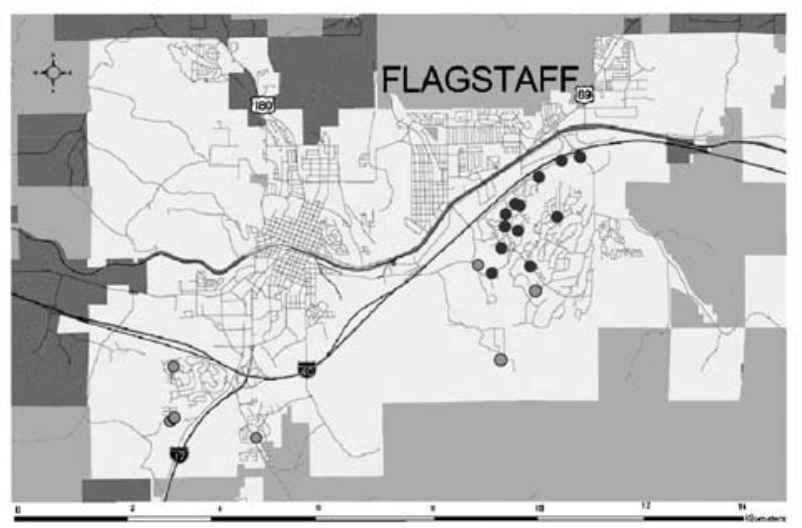

Figure 1. Temporal and geographic distribution of rabies outbreak in Flagstaff, Arizona. A) Timeline and control measures. TVR: trap, vaccinate, release program. B) Geographic location of rabid skunks (dark gray dots = subclade 1, light gray dots = subclade 2 ). 
Table. Animals from Flagstaff submitted for rabies diagnosis, January-July, 2001

\begin{tabular}{lccc}
\hline Animal & Scientific name & $\begin{array}{c}\text { No. } \\
\text { submitted }\end{array}$ & $\begin{array}{c}\text { No. } \\
\text { rabid }\end{array}$ \\
\hline Skunk & Mephitis mephitis & 145 & 19 \\
Bat & (Multiple spp.) & 22 & 2 \\
Domestic cat & Felis domesticus & 12 & 0 \\
Gray fox & $\quad$ Urocyon & 9 & 0 \\
Domestic dog & Cinereoargenteus & & \\
Squirrel & Canis familiaris & 9 & 0 \\
Coyote & Species unknown & 8 & 0 \\
Raccoon & Canis latrans & 4 & 0 \\
Porcupine & Procyon lotor & 2 & 0 \\
Prairie dog & Erethizon dorsatum & 2 & 0 \\
Badger & Taxidea taxus & 2 & 0 \\
Opossum & Didelphis virginiana & 1 & 0 \\
Bobcat & Lynx rufus & 1 & 0 \\
Total & & 218 & 0 \\
\hline
\end{tabular}

22 tested bats. Although most (18 [95\%]) of the rabid skunks were identified and reported by lay citizens, no contact between these skunks and humans or domestic animals was reported.

Local baseline population estimates were not available to indicate whether skunk demography affected disease attributes. Synchronous with this outbreak, independent epizootic activity caused by well-established skunk RABVV was documented in southern Arizona, which suggests that regional skunk epizootiologic dynamics were similarly affected. Skunks' seasonal behavior may have contributed to transmission events. This epizootic was initially recognized when a dead skunk appeared in a snowcovered backyard, during a season when skunks are in communal dens. Given an incubation period of 2 months, most transmission would have occurred between late autumn (when skunks are in their dens) and late winter (when they are mating).The Flagstaff epizootic peak coincided with nationwide seasonal trends of rabid skunks (1). Enhanced postepizootic surveillance in Flagstaff did not detect additional rabid terrestrial mammals for the next 3 years. However, in 2004, a total of 5 skunks found in the initially affected east Flagstaff neighborhood and 1 fox 28 $\mathrm{km}$ south of Flagstaff were infected with the same bat RABVV (10).

Viruses isolated from the rabid skunks exhibited monoclonal antibody patterns similar to RABVV associated with big brown (Eptesicus fuscus) and Myotis bats in the western United States (11). These are among the most abundant bat species in Arizona and often roost in houses and outbuildings; however, no bat colonies were found in association with any of the rabid skunks. Restriction digests of PCR amplicons from the rabid skunks did not match patterns known for RABVV from North American terrestrial reservoirs (12). Phylogenetic analysis of a 300bp region of the $\mathrm{N}$ gene showed that the Flagstaff skunk
RABVV was identical (100\%) to Arizona bat RABVV (online Appendix Table, available from http://www.cdc. gov/ncidod/EID/vol12no08/05-1526-appT.htm,and Figure 2A), and differed by $22 \%$ from skunk and gray fox RABVV. A monophyletic clade (clade A) of 8/8 big brown, 5/14 Myotis, and 1/6 southern yellow (Lasiurus ega) bats shared $>95 \%$ identity with Flagstaff skunk RABVV. An additional 44 samples, representing 11 bat species, differed by $>8 \%$ from Flagstaff skunk RABVV.

An analysis of clade A, which incorporates N and G genes, indicated that the Flagstaff skunk RABVV were more closely related to 2 bat RABVV (E. fuscus from Coconino County, M. velifer from Maricopa County) collected in 1999 and 1997 than to the 2 bat RABVV collected locally during the outbreak. In clade $B$, subclade 1 RABVV were collected from January through early April

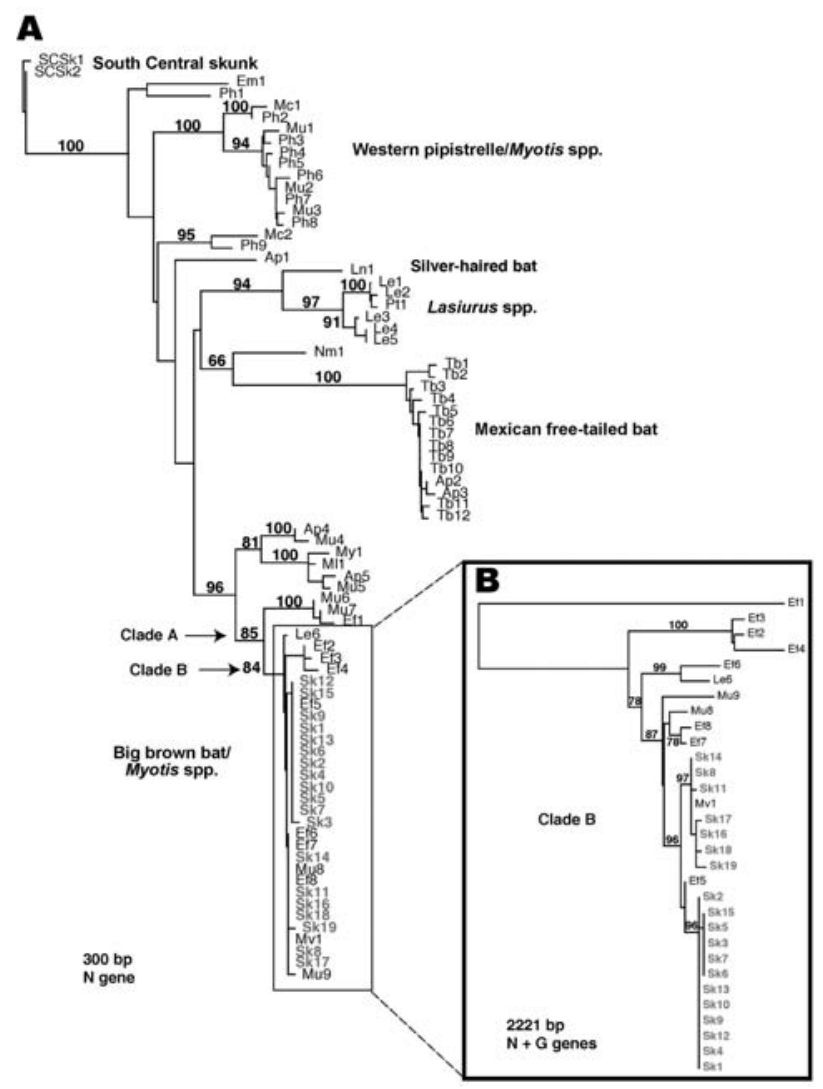

Figure 2. A) Phylogenetic tree of the 19 rabid skunk isolates and representative samples of known rabies virus variants (RABVV) from Arizona based on $300 \mathrm{bp}$ of the nucleoprotein $(\mathrm{N})$ gene (GenBank accession no. AY170226-304). B) Detailed analyses of clade including all 19 skunk isolates (clade B) based on $2221 \mathrm{bp}$ of the $\mathrm{N}$ and glycoprotein (G) genes (GenBank accession no. AY170397-438). Phylogenetic analyses used PAUP* software (version 4.0b2, Sinauer Associates, Sunderland, MA, USA; 2000] using the neighbor-joining search algorithm (minimum evolution) with maximum likelihood to estimate Ti:Tv ratio and nucleotide base frequencies (HKY85 model). Numbers at tree nodes indicate nonparametric bootstrap proportions based on 1,000 replicates. 
from the northeastern region of the outbreak, whereas subclade 2 RABVV were collected from early March through July from the southeastern and western regions of the outbreak (Figure 1). However, phylogenetic data do not support a wavelike spread from northeast to west because this would require nesting of subclade 1 within subclade 2 . In contrast, both subclades exhibit independently derived mutations. East-to-west epizootic movement of RABVV within subclade 2 (sk16-19 form a monophyletic clade nested within subclade 2) during April is supported by the data and may be related to dispersal of infected skunks along river corridors or translocation by humans. One person reported trapping, moving, and releasing a skunk before the outbreak was known in the community. Alternatively, apparent shifts may be an artifact of intensified public awareness and reporting. Lack of sampling in the uninhabited forest between the eastern and western foci limits our ability to discriminate among these hypotheses.

\section{Conclusions}

This is the largest recorded cluster of bat RABVV infection in terrestrial mammals. Investigation of this novel outbreak showed evolution in action with the emergence of an RABVV that successfully adapted from Chiroptera to Carnivora. Previously documented clusters involving 3-4 to terrestrial mammals infected with a single insectivorous bat rabies virus variant did not corroborate sustained transmission (12). Although $>1$ skunk may have been exposed to a single rabid bat, it is highly unlikely that each skunk was exposed to the same bat or that multiple bat-skunk exposures occurred. We could not ascertain the complete scope of this outbreak or whether it was the index event. Phylogenetic analyses support the evolution of 2 independent lineages, suggesting establishment for months or years. Additionally, virus isolation from salivary glands of 5 affected skunks and the reappearance of rabid skunks with the same RABVV in 2004 support the probability of independent transmission.

The recognition of this epizootic can be credited to a coordinated laboratory-based disease surveillance program to monitor sick and dead wildlife for potential zoonoses (plague, tularemia, rabies) even in situations lacking human or pet exposures. Comprehensive animal disease surveillance provides direct benefits to public health and animal health by promoting early recognition of risk and opportunities for disease control and prevention interventions.

Unpredictable health threats related to emerging zoonoses, especially those involving wildlife reservoirs, pose notable surveillance and control challenges (13-15). Recent bioterrorism initiatives emphasize integration of human and animal disease surveillance, and enhanced lab- oratory capacity, as essential functions in zoonosis detection (13). Rabies surveillance and control programs serve as historic prototypes for effective, long-term, public health programs. Quintessential zoonotic disease programs require innovative and expanded capacities, commitments to public health and veterinary laboratory infrastructure, and appropriate interagency and interdisciplinary coordination and communication.

\section{Acknowledgments}

We thank the citizens of Flagstaff and a large multiagency task force, who contributed to managing this outbreak, including Flagstaff City Police Department Animal Control Program, B. Worgess, P. Barbeau, C. Levy, J. Henderson, M. VanDeGriend, D. Bergman, Northern Arizona University, R. Rosatte, Texas Department of State Health Services Rabies Laboratory, M. Niezgoda, L. Orciari, J. Dragoo, Arizona Department of Game and Fish, Coconino County Humane Society, and the Coconino County Board of Supervisors. We also thank Doug Beckner for the timeline graphic.

Dr Leslie was Arizona's state public health veterinarian during 1995-2002 and currently holds the same position in Washington State. Her work is focused on surveillance, investigation, and control of zoonotic and vectorborne diseases. She chairs the National Association of State Public Health Veterinarian's Compendium of Animal Rabies Prevention and Control Committee.

\section{References}

1. Krebs JW, Mandel EJ, Swerdlow D, Rupprecht CE. Rabies surveillance in the United States during 2003. J Am Vet Med Assoc. 2004;225:1837-49.

2. Brass DA. Rabies in bats: natural history and public health implications. Ridgefield (CT): Livia Press; 1994.

3. Messenger SL, Smith JS, Orciari LA, Yager PA, Rupprecht CE. Emerging patterns of rabies deaths and increased viral infectivity. Emerg Infect Dis. 2003;9:151-4.

4. Mondul AM, Krebs JW, Childs JE. Trends in national surveillance for rabies among bats in the United States (1993-2000). J Am Vet Med Assoc. 2003;222:633-9.

5. Anderson LJ, Nicholson MB, Tauxe RV, Winkler WG. Human rabies in the United States, 1960 to 1979: epidemiology, diagnosis, and prevention. Ann Intern Med. 1984;100:728-35.

6. Noah DL, Drenzek CL, Smith JS, Krebs JW, Orciari L, Shaddock J, et al. Epidemiology of human rabies in the United States, 1980-1996. Ann Intern Med. 1998;128:922-30.

7. Rohde RE, Mayes BC, Smith JS, Neill SU. Bat rabies, Texas, 1996-2000. Emerg Infect Dis. 2004;10:948-52.

8. McQuiston JH, Yager PA, Smith JS, Rupprecht CE. Epidemiologic characteristics of rabies virus variants in dogs and cats in the United States, 1999. J Am Vet Med Assoc. 2001;218:1939-42.

9. Badrane H, Tordo N. Host switching in Lyssavirus history from the Chiroptera to the Carnivora orders. J Virol. 2001;75:8096-104.

10. Arizona Department of Health Services. Rabies in Arizona, 2004. [cited 2006 Mar 26]. Available from http://www.azdhs.gov/phs/oids/ vector/rabies/rab04.htm 
11. Smith JS, Reid-Sanden FL, Roumillat LF, Trimarchi C, Clark K, Baer GM, et al. Demonstration of antigenic variation among rabies virus isolates by using monoclonal antibodies to nucleocapsid proteins. J Clin Microbiol. 1986;24:573-80.

12. Rohde RE, Neill SU, Clark KA, Smith JS. Molecular epidemiology of rabies epizootics in Texas. Clin Diagn Virol. 1997;8:209-17.

13. Messenger SL, Rupprecht CE, Smith JS. Bats, emerging virus infections, and the rabies paradigm. In: Kunz TH, Fenton MB, editors. Bat ecology. Chicago: The University of Chicago Press; 2003. p. 622-79.

14. Centers for Disease Control and Prevention. Core functions and capabilities of state public health laboratories: a report of the Association of Public Health Laboratories. MMWR Recomm Rep. 2002;51 (RR14):1-8.
15. Hanlon CA, Childs JE, Nettles VF. Recommendations of a national working group on prevention and control of rabies in the United States. Article III: rabies in wildlife. J Am Vet Med Assoc. 1999;215:1612-8.

Address for correspondence: Mira J. Leslie, Washington Department of Health, Communicable Disease Epidemiology, 1610 NE 150th St, MS K17-9, Shoreline, WA 98155-9701 email: Mira.Leslie@doh.wa.gov

Use of trade names is for identification only and does not imply endorsement by the Public Health Service or by the U.S. Department of Health and Human Services.

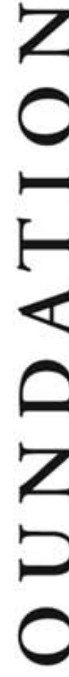

II

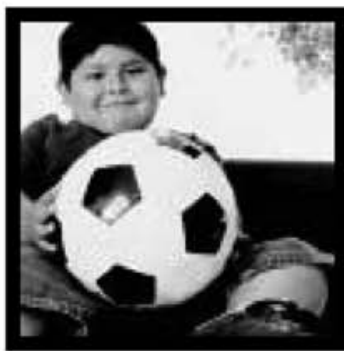

The CDC Foundation helps the

Centers for Disease Control and

Prevention fight the most urgent

health threats, like avian flu,

bioterrorism and obesity

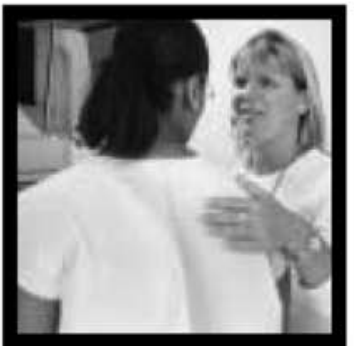

Find out how you can partner

with CDC to promote a safer,

healthier world

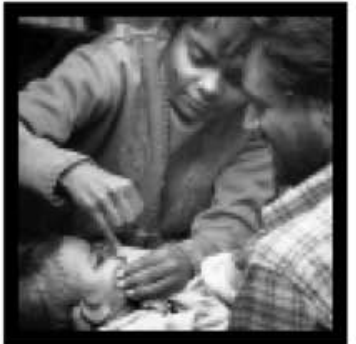

Private support is critical to

our mission

www.cdcfoundation.org 